Research, Society and Development, v. 7, n. 8, p. 01-17, e378324, 2018

ISSN 2525-3409 (CC BY 4.0)

\title{
Mestrados para a Formação de Docentes: um locus de (re) construção e de aprendizagem
}

Masters for Teacher Training: a locus of (re) construction and learning

Andreia Aparecida Guimarães Strohschoen

Universidade do Vale do Taquari UNIVATES, Brasil

E-mail: aaguim@univates.br

Gabriela Luisa Henz

Universidade do Vale do Taquari UNIVATES, Brasil

E-mail: Gabriela.henz@universo.univates.br

Alessandra Mocellim Gerevini

Universidade do Vale do Taquari UNIVATES, Brasil

E-mail: amgerevini@universo.univates.br

Silvana Neumann Martins

Universidade do Vale do Taquari UNIVATES, Brasil

E-mail: smartins@univates.br

Recebido: 15/03/2018 - Aceito: 23/04/2018

\section{Resumo}

O presente estudo objetiva analisar como o desenvolvimento de estratégias pedagógicas inovadoras vinculadas às Metodologias Ativas de ensino e de aprendizagem estão sendo levadas à prática em pesquisas produzidas por alunos de pós graduação em nível de Mestrado de uma Universidade localizada no interior do estado do Rio Grande do Sul/Brasil. Trata-se de um estudo de cunho qualitativo, com abordagem exploratória e descritiva. Para a coleta de dados realizou-se revisão bibliográfica da produção acadêmica a partir de 141 dissertações de Mestrado oriundos de dois programas de Mestrados oferecidos pela Universidade. Os dados foram coletados através das Biblioteca virtual da Universidade. Do total de dissertações encontradas 43 apresentavam indicativos claros de uso de metodologias ativas. Estas foram analisadas e percebeu-se que as metodologias ativas impulsionaram positivamente os alunos, pois, instigou-os a serem mais interessados; participativos na sala de aula, além de desenvolverem a criticidade e autonomia dos mesmos.

Palavras-chave: Dissertações acadêmicas; Revisão bibliográfica; Metodologias ativas. 


\section{Abstract}

The present study aims to analyze how the development of innovative pedagogical strategies linked to active teaching and learning methodologies are being carried out in the researches produced by postgraduate students at a Master's level of a University located in the interior of Rio Grande do Sul/Brazil. This is a qualitative study, with a descriptive exploratory approach. For the data collection, a bibliographic review of the academic production was carried out from 141 Master's dissertations from two Master's programs offered by the University. Data were collected through the University's Virtual Library. Of the total number of dissertations found, 43 presented clear indications of the use of active methodologies. These were analyzed and it was noticed that the active methodologies positively stimulated the students, as it instigated them to be more interested; in the classroom, in addition to developing their criticality and autonomy.

Keywords: Academic Dissertations. Literature review. Active methodologies.

\section{Introdução}

É possível perceber-se com base nos indicadores de educação disponíveis que o Brasil apresenta fragilidades quanto a este assunto, tendo diversos motivos, dentre eles, falta de professores, baixa qualidade do ensino ou também por uma certa desmotivação vinda dos professores, entre outros fatores (BRASIL, 2009). Nesse contexto, inserem-se as discussões com relação à inovação no ensino, como as denominadas metodologias ativas, que podem proporcionar um ambiente de motivação educacional. Estas metodologias são consideradas como processos interativos de busca e produção de conhecimento, onde os estudantes juntamente com os professores realizam análises, estudos, pesquisas e decisões, as quais são tomadas a nível individual ou coletiva; sendo que estas buscam encontrar soluções para um determinado problema. Observa-se que o ensino voltado para as metodologias ativas pode ser considerado como colaborativo, usa o contexto ativo por parte do estudante visando o aprendizado, permite a aprendizagem entre pares ou em grupo e ainda desenvolve o estudo individualizado. Sendo estas características importantes para o processo de aprendizagem dinâmica dos estudantes, desempenhando um papel vital na criação de novos conhecimentos (PINTO et al., 2013).

Assim, objetiva-se com este estudo, analisar como o desenvolvimento de estratégias pedagógicas inovadoras relacionadas às Metodologias Ativas de ensino e de aprendizagem 
tem sido levado à prática nas pesquisas produzidas por mestrandos vinculados ao Mestrado em Ensino e ao Mestrado Profissional em Ensino de Ciências Exatas de uma Universidade do interior do Estado do Rio Grande do Sul. Busca-se problematizar como as propostas de ensino presentes nas dissertações de Mestrado analisadas impactam no cotidiano da sala de aula e como influenciam os alunos envolvidos.

\section{Referencial Teórico}

Dentro do âmbito escolar, o professor encontra-se em uma situação extremamente desafiadora, pois ao mesmo tempo deve analisar o método de ensino e de aprendizagem selecionado e pensar em estratégias decorrentes destes processos. Observa-se que o estudante pode passar por um processo de transformação profunda através das metodologias ativas utilizadas pelo professor na sala de aula, passando assim por um processo de amadurecimento da situação na qual o estudante se encontrava (ANASTASIOU, 2014).

Nesse sentido, a importância da aprendizagem inicia-se "quando situadas no contexto de suas ocorrências, e os saberes são transformados, e não substituídos" (SCHUCK et al., 2016, p.495). De acordo com os mesmos autores, a sociedade é moldada pela aprendizagem, se moldando assim pela aprendizagem, requerendo concepções integradoras e ações coletivas, apoiadas em processos investigativos.

Para o professor é importante pensar em propor inovações e estratégias para os docentes oferecendo novos caminhos e novas metodologias de ensino, favorecendo o desenvolvimento de motivação e autonomia (DIESEL; BALDEZ; MARTINS, 2017). As metodologias ativas ampliam o campo de construção do conhecimento dos estudantes, principalmente por instigar os mesmos a terem um pensamento mais crítico e autônomo (GOMES, 2010).

Assim, estas metodologias são definidas como atividades propostas pelo professor oferecendo oportunidade para o aluno refletir sobre o que está fazendo (BONWELL; EISON, 1991; SILBERMAN, 1996). A partir disso, os alunos devem estar envolvidos com a proposta de ensino, participando assim, ativamente do que está sendo proposto pelo professor, questionando, discutindo e interagindo ativamente com a proposta oferecida pelo professor (BARBOSA; MOURA, 2013).

Neste caso, a avaliação se diferencia daquelas oriundas de uma aula tradicional, pois passa a ter um foco na aprendizagem do aluno e não somente nos resultados que se obteriam 
com tal proposta (GEMIGNANI, 2012). Corroborando com essa afirmação, Barbosa e Moura (2013) explicam que, com o uso das metodologias ativas na sala de aula:

"O aluno interage com o assunto em estudo - ouvindo, falando, perguntando, discutindo, fazendo e ensinando - sendo estimulado a construir o conhecimento ao invés de recebê-lo de forma passiva do professor. Em um ambiente de aprendizagem ativa, o professor atua como orientador, supervisor, facilitador do processo de aprendizagem, e não apenas como fonte única de informação e conhecimento" (p.55).

Assim, a aprendizagem do estudante não se limita a uma aula especialmente expositiva e decorada, mas com sua participação e seu envolvimento na metodologia proposta pelo professor. Nessa situação, os professores passam de transmissores do conhecimento para um facilitador - também conhecido como orientador - da aprendizagem dos alunos, orientando-os em relação à realização de pesquisas, à construção de criticidade e autonomia, buscando atingir os objetivos estabelecidos coletivamente (BERBEL, 2011).

Com a utilização das metodologias ativas em sala de aula, o foco da aprendizagem passa do professor para o aluno, sendo o aluno o responsável por sua aprendizagem (SOUZA; IGLESIAS; PAZIN-FILHO, 2014). Neste contexto, observa-se como fundamental que o professor e o aluno busquem um relacionamento de comprometimento durante o processo de ensino e aprendizagem pois, como explica Masetto (2003, p.22):

“... é importante que o professor desenvolva uma atitude de parceria e corresponsabilidade com os alunos, que planejam o curso junto, usando técnicas em sala de aula que facilitem a participação e considerando os alunos como adultos que podem se responsabilizar por seu período de formação profissional”.

Há características relacionadas às metodologias ativas no âmbito da educação acadêmica, como por exemplo o fato de que neste processo ocorre o incentivo para os estudantes serem protagonistas do seu próprio processo de ensino e aprendizagem, mudando assim a sua postura, tornando-se mais dedicado, autônomo e responsável, além de também buscar inserir nas relações sociais dos alunos o que aprenderam em aula (BERBEL, 2011).

As metodologias ativas proporcionam a problematização como estratégia de ensino e de aprendizagem. Berbel (2011, p.29) afirma que: 
“[...] a problematização pode levar o aluno ao contato com as informações e à produção do conhecimento, principalmente, com a finalidade de solucionar os impasses e promover o seu próprio desenvolvimento. Aprender por meio da problematização e/ou da resolução de problemas de sua área, portanto, é uma das possibilidades de envolvimento ativo dos alunos em seu próprio processo de formação".

De acordo com a mesma autora, para que as estratégias de ensino se concretizem com êxito, os participantes do processo precisam compreender as estratégias de ensino, acreditarem no próprio potencial pedagógico além de estarem preparados para trabalhar de acordo com a proposta da metodologia (BERBEL, 2011).

Dentre as estratégias utilizadas nas metodologias ativas, alguns exemplos são:

- Aprendizagem Baseada em Problemas (PBL): metodologia onde o professor apresenta aos alunos situações-problemas contendo temas definidos pelo professor. Pode ser também denominada Resolução de problemas. A partir das situaçõesproblemas, os alunos irão estudar e refletir sobre a situação, de forma individual ou coletiva e, posteriormente, discutir esse problema com o restante da turma (MUNHOZ, 2015; SOBRAL; CAMPOS, 2012).

- Portfólio: o portfólio é um material construído pelo aluno e vai ser um instrumento (caderno, pasta, álbum) onde este irá reunir resumos de textos, sínteses de temas estudados, relatórios, avaliações escritas, anotações e demais tarefas realizadas pelo próprio aluno afim de analisar, avaliar, refletir e apresentar atividades realizadas em um determinado tempo (WALL, PRADO, CARRARO, 2008).

- World Café: estratégia que tem como principal foco a conversação sobre determinado tema. Os participantes são separados em grupos e recebem um tema para discutir. Após a discussão do tema, cada grupo deve apresentar para o restante da turma o que foi discutido (MARTINEZ; SOUZA; TONIOSSO, 2015).

- Problematização: a problematização ocorre quando o aluno é incentivado a identificar dificuldades do seu meio social, as quais podem ser transformadas em situações-problema para estudo. Então é realizada uma síntese do problema, geralmente após os alunos discutirem e estudarem os problemas em grupos. $\mathrm{Na}$ segunda fase o aluno irá refletir sobre as possíveis causas, consequências e soluções do problema. A terceira fase é a investigação, onde os alunos irão buscar informações sobre o problema e, por fim, realizarão as hipóteses de solução e aplicar estas hipóteses na realidade (BERBEL, 1998). 
- Sala de aula invertida: estratégia na qual os conteúdos e as instruções são enviados por alguma plataforma virtual de aprendizagem para os alunos antes da aula presencial. Desta forma, a sala de aula passa a ser um local onde são desenvolvidos os conteúdos que já foram estudados previamente pelos alunos, por meio de atividades como discussões em grupo, criação de projetos, resoluções de problemas, atividades experimentais, jogos didáticos, entre outros (VALENTE, 2014; BERGMAN, SAMS, 2016).

- Peer Instruction: o professor escolhe conteúdos que devem ser trabalhados em sala de aula, incentiva os alunos a estudarem antes da aula, utilizando diferentes materiais, como vídeos, livros, artigos. Em aula, os alunos respondem a um conjunto de questões sobre o tema. O professor verifica as respostas imediatamente e, durante a aula mesmo, analisa as dificuldades enfrentadas pelos alunos. Os alunos têm um tempo predefinido pelo grupo para pensarem sobre cada questão e devem formular suas próprias respostas, buscando relacionar as questões com suas leituras prévias. Dependendo da resposta, os alunos passam dois ou três minutos discutindo suas respostas em grupos de 3 a 4 componentes, na tentativa de chegar a um consenso sobre a resposta correta. Este processo estimula os alunos a pensarem sobre os argumentos a serem desenvolvidos, e permite que eles, da mesma forma que o professor, possam avaliar o nível de compreensão sobre os conceitos antes mesmo do término daquela aula (VALENTE, 2014; MAZUR, 2015).

Salienta-se que o protagonismo do aluno é a base das metodologias ativas, o que acaba permitindo desenvolver habilidades e competências indispensáveis para a construção da autonomia intelectual e social do aluno. Este exercita sua capacidade de reflexão e ação em relação à realidade em que está inserido (PINTO et al., 2013).

\section{Percurso Metodológico}

A presente pesquisa é considerada qualitativa, por valorizar "o contato direto e prolongado do pesquisador com o ambiente e a situação que está sendo estudada" (GODOY, 1995 p. 57). Tem como principal instrumento a observação da realidade na qual o pesquisador está inserido. É uma pesquisa descritiva, pois seu principal objetivo é entender e descrever os instrumentos analisados, para compreendê-los de formas variadas, além de relacionar as 
características de um grupo ou fenômeno com os dados coletados utilizando fundamentações teóricas (GIL, 2008).

Primeiramente, foi realizada a seleção do material de pesquisa, 141 dissertações de mestrado, sendo 26 dissertações oriundas do Programa de Pós-graduação Mestrado em Ensino (PPGEnsino) e 115 oriundas do Programa de Pós-graduação Mestrado Profissional em Ensino em Ciências Exatas (PPGECE) que foram defendidas do ano de 2014 até março de 2017. Todas estas dissertações estão disponíveis online no repositório de dissertações da Instituição de Ensino Superior a que estão vinculadas.

A análise preliminar das dissertações foi realizada por meio de leitura do resumo e da metodologia adotada no desenvolvimento das dissertações. Utilizou-se o seguinte critério para a seleção das dissertações a serem lidas na íntegra: presença de indicativos de uso de estratégias vinculadas às metodologias ativas no estudo.

Após esta leitura flutuante, foram identificadas as dissertações que abordavam claramente o uso de metodologias ativas. Estas dissertações foram lidas e analisadas integralmente, buscando-se reconhecer os impactos do uso de estratégias norteadas por metodologias ativas em sala de aula.

\section{Resultados e Discussão}

Ao analisar as dissertações neste estudo, foram encontradas 43 (30,5\%) dissertações que apresentavam evidências de uso de estratégias pedagógicas norteadas por metodologias ativas, com alunos de diferentes níveis de ensino. Selecionamos para apresentar neste artigo algumas produções que apresentavam claramente em seu resumo e descrição de atividades, o uso de estratégias pedagógicas inovadoras, buscando a participação ativa dos alunos no processo de construção do conhecimento. Apresentamos no quadro a seguir algumas destas dissertações analisadas:

Quadro 1 - Estratégias norteadas por metodologias ativas utilizadas em sala de aula que foram identificadas nas dissertações de mestrado analisadas neste estudo

\begin{tabular}{|c|c|c|}
\hline Autores & Metodologia & Resultados \\
\hline MAGEDANZ, 2009 & $\begin{array}{l}\text { A estratégia utilizada foi Sala } \\
\text { de Aula Invertida. Os sujeitos }\end{array}$ & $\begin{array}{l}\text { O professor percebeu maior } \\
\text { interação e participação dos }\end{array}$ \\
\hline
\end{tabular}




\begin{tabular}{|c|c|c|}
\hline & $\begin{array}{l}\text { da pesquisa foram alunos de } \\
\text { uma turma de } 3^{\circ} \text { ano do ensino } \\
\text { médio de uma escola estadual } \\
\text { de um município no interior do } \\
\text { Rio Grande do Sul. O professor } \\
\text { disponibilizou materiais } \\
\text { postados em um Ambiente } \\
\text { Virtual de Aprendizagem } \\
\text { (AVA) os alunos deviam ler e } \\
\text { refletir sobre o conteúdo, } \\
\text { participar do chat, dos fóruns e } \\
\text { das atividades online propostas } \\
\text { pelos professores. Em sala de } \\
\text { aula, o professor realizava } \\
\text { atividades de discussão com os } \\
\text { alunos em pequenos grupos. }\end{array}$ & $\begin{array}{l}\text { alunos nas atividades depois } \\
\text { de utilizar a sala de aula } \\
\text { invertida além de ter } \\
\text { proporcionado uma maior } \\
\text { compreensão dos conteúdos de } \\
\text { matemática por eles. }\end{array}$ \\
\hline SIQUEIRA, 2009 & $\begin{array}{l}\text { Foi realizada a } \\
\text { problematização com alunos } \\
\text { do ensino fundamental. Após } \\
\text { observações nas proximidades } \\
\text { do bairro onde a escola está } \\
\text { localizada, os alunos elencaram } \\
\text { problemas para serem } \\
\text { discutidos em grupos e } \\
\text { desenvolvidos seguindo as } \\
\text { orientações da } \\
\text { problematização. }\end{array}$ & $\begin{array}{l}\text { A estratégia contribuiu para } \\
\text { que os alunos se sentissem } \\
\text { mais confiantes ao socializar as } \\
\text { atividades feitas em sala de } \\
\text { aula com a comunidade escolar } \\
\text { a com a família através de } \\
\text { campanhas, como no caso da } \\
\text { separação e coleta de lixo. Os } \\
\text { alunos participaram das aulas } \\
\text { com mais interesse e } \\
\text { entusiasmo além disso, esta } \\
\text { estratégia proporcionou troca } \\
\text { de experiências entre os alunos } \\
\text { e maior interação entre os } \\
\text { mesmos. }\end{array}$ \\
\hline DAROID, 2010 & $\begin{array}{l}\text { A estratégia escolhida foi } \\
\text { Pesquisa em sala de aula e foi } \\
\text { realizada com alunos do Ensino } \\
\text { Médio, de uma Escola Pública } \\
\text { do Vale do Taquari - RS. Os } \\
\text { alunos realizaram } \\
\text { questionários, relatórios, } \\
\text { atividader de pesquisa } \\
\text { bibliográfica, observações e } \\
\text { seminários. }\end{array}$ & $\begin{array}{l}\text { Observou-se que a pesquisa no } \\
\text { ensino de Física possibilita a } \\
\text { construção de aprendizagens } \\
\text { conceituais, procedimentais e } \\
\text { atitudinais evidenciadas pela } \\
\text { evolução de concepções sobre } \\
\text { os fenômenos presentes no } \\
\text { cotidiano, pela capacidade de } \\
\text { estabelecer relações entre esses } \\
\text { fenômenos e os conteúdos } \\
\text { curriculares, pela qualificação } \\
\text { das habilidades de convívio } \\
\text { social e comunicação }\end{array}$ \\
\hline
\end{tabular}




\begin{tabular}{|l|l|}
\hline SCORSATTO, 2010 & $\begin{array}{l}\text { Foi realizada Aprendizagem } \\
\text { baseada em Problemas com } \\
\text { os alunos do Ensino Médio, do } \\
\text { município de Fontoura } \\
\text { Xavier/RS. Foram realizadas } \\
\text { atividades relacionadas ao } \\
\text { conteúdo de Energia, sendo os } \\
\text { alunos instigados a discutirem } \\
\text { diferentes situações problema. } \\
\text { Estas foram desenvolvidas } \\
\text { pelos alunos realizando } \\
\text { montagem de tabela referente } \\
\text { aos objetos eletroeletrônicos } \\
\text { existentes nas residências; } \\
\text { cálculo dos gastos referentes a } \\
\text { esses aparelhos; visitação a } \\
\text { uma usina hidrelétrica; dentre } \\
\text { outras atividades. }\end{array}$ \\
\hline
\end{tabular}

HENNEMANN, 2012

ROSSI, 2012 interpessoal, pelo respeito às diferenças e, principalmente, pela possível mudança do olhar sobre o ensino de Física.

Com a utilização desta estratégia, destaca-se que a proposta gerou nos estudantes um despertar em relação à questão ambiental. $\mathrm{O}$ desenvolvimento das atividades possibilitou os estudantes a refletirem sobre a importância de se economizar energia, preservando assim os recursos ambientais. Os estudantes conseguiram relacionar os conteúdos desenvolvidos nas aulas com seu cotidiano.

A estratégia escolhida para a presente pesquisa foi a Aprendizagem Baseada em Problemas, com uma turma de alunos do Ensino Médio de um Colégio da Rede Particular de Ensino no município de Lajeado/RS. Foram realizadas saídas a campo a uma Hidrelétrica; confecções de aquecedores; produção de etanol a partir do extrato do abacaxi; práticas realizadas no laboratório de química; dentre outras atividades. Todas estas atividades partiram de situações problemas que configuram como desafios para os alunos.

Essas atividades favoreceram a aproximação do conteúdo abordado em sala de aula com a realidade dos alunos, por meio de atividades práticas diferenciadas, desafiadoras. Estas estimularam os estudantes a refletirem e buscarem expor suas ideias de forma autônoma, crítica e consciente, tornando a aprendizagem mais atrativa para os estudantes.

As estratégias escolhidas foram: Jogos Didáticos com
Observou-se que as diferenças culturais podem ser superadas 
alunos do Ensino Fundamental de uma Escola Municipal na cidade de Nova Prata/RS. Foi realizado um jogo de boliche numérico onde os alunos estipularam valores numéricos para cada uma das garrafas a serem utilizadas como pinos de boliche, realizarem cálculos a fim de descobrirem a pontuação atingida e registrarem por escrito a formalização do cálculo ou raciocínio de que se valeram para chegar ao resultado. Foi realizado também o jogo do canudinho; dentre outros jogos.

MORO, 2015

KAFER, 2015
O estudo foi realizado com alunos do ensino médio de uma escola privada do município de Erechim/RS. As estratégias de ensino foram Mapas Conceituais e Simulações Computacionais. A turma foi dividida em grupos e realizaram simulações do Energy 2D sobre condução e convecção e simulações do $\mathrm{PhET}$ sobre radiação. Após trabalhar com as simulações foi realizado um mapa conceitual relacionando os conteúdos vistos nas simulações com o cotidiano.

As estratégias pedagógicas desenvolvidas foram: Mapas Conceituais e uso de um Ambiente Virtual de Aprendizagem (AVA). Participaram desta pesquisa alunos do Ensino Médio Técnico Integrado do Curso de Informática, de uma escola pública do município de por meio de uma prática pedagógica apoiada em princípios de respeito ao outro, de convívio com diferenças. Além disso, a escolha por estratégias de ensino pautadas na ludicidade, em regras decididas coletivamente e conteúdos conectados com a realidade dos estudantes tornam significativos os caminhos para o ensino de Ciências Exatas, especialmente de matemática.

Observou-se que os alunos estavam motivados e predispostos para trabalhar com as atividades experimentais e as simulações, realizando-as com entusiasmo e demonstrando interesse, favorecendo a ocorrência da aprendizagem significativa.

Observou-se que os alunos participaram ativamente das atividades propostas, inclusive àquelas a distância, por meio do AVA. Os mapas conceituais construídos evidenciaram a construção de conhecimento pelos alunos. 
ISSN 2525-3409 (CC BY 4.0)

\begin{tabular}{|c|c|c|}
\hline & $\begin{array}{l}\text { Alegrete/RS. } \\
\text { desenvolvidas } \\
\text { atividades utilizando o AVA, } \\
\text { inclusive a produção de Mapas } \\
\text { conceituais dos conteúdos } \\
\text { desenvolvidos em aula. }\end{array}$ & \\
\hline MARTINS, 2016 & $\begin{array}{l}\text { Para a pesquisa foi realizado } \\
\text { Mapas Conceituais e a } \\
\text { Problematização com alunos } \\
\text { do Instituto Maranhense de } \\
\text { Ensino e Cultura - IMEC do } \\
\text { Curso de Ciências Contábeis. } \\
\text { Os alunos trabalharam } \\
\text { atividades utilizando a Planilha } \\
\text { Eletrônica Microsoft Excel } \\
\text { 2013. }\end{array}$ & $\begin{array}{l}\text { Percebeu-se, com o uso das } \\
\text { práticas pedagógicas } \\
\text { inovadoras os alunos tornaram- } \\
\text { se mais atentos e conscientes } \\
\text { na instrumentalização e na } \\
\text { compreensão de conteúdos } \\
\text { matemáticos e que } \\
\text { relacionaram os conteúdos com } \\
\text { o cotidiano. }\end{array}$ \\
\hline SOUZA, 2016 & $\begin{array}{l}\text { As estratégias utilizadas foram } \\
\text { Jogos Didáticos } \\
\text { Aprendizagem Baseada em } \\
\text { Problemas, desenvolvidas com } \\
\text { alunos da Educação Infantil do } \\
\text { município de Moju/PA. Foram } \\
\text { desenvolvidas situações de } \\
\text { aprendizagem pelo professor } \\
\text { para ver como os alunos } \\
\text { realizariam as situações de } \\
\text { aprendizagens }\end{array}$ & $\begin{array}{l}\text { Com as estratégias utilizadas, } \\
\text { percebeu-se que os alunos } \\
\text { participaram ativamente, } \\
\text { discutiram, emitiram opiniões e } \\
\text { ideias, questionaram as ideias } \\
\text { dos colegas e contribuíram na } \\
\text { discussão dos conhecimentos } \\
\text { matemáticos em estudo. Em } \\
\text { cada situação de aprendizagem } \\
\text { em que os alunos se } \\
\text { envolveram, expondo ideias e } \\
\text { teorias a respeito do conceito } \\
\text { matemático oportunizado, pode } \\
\text { ter ocorrido crescimento, } \\
\text { favorecendo o Protagonismo } \\
\text { Infantil. }\end{array}$ \\
\hline
\end{tabular}

Fonte: dos autores, 2017.

A partir da análise das dissertações observou-se que as principais estratégias pedagógicas que foram identificadas de forma clara nas dissertações analisadas foram: aproximações com a Aprendizagem Baseada em Problemas (ABP), também denominada em algumas dissertações como Resolução de problemas; Problematização, Jogos didáticos, e Mapas conceituais. Outras atividades também encontradas foram: Aprendizagem Baseada em Projetos, Sala de aula invertida, Diário de Bordo; Peer instruction; Simulações; Ambiente virtual de Aprendizagem; Júri simulado; World café; dentre outras estratégias. 
Analisando as descrições apresentadas nas dissertações observa-se que as estratégias pedagógicas utilizadas favoreceram a aprendizagem dos alunos, desde o desenvolvimento da autonomia, desenvolvimento do senso crítico, além de contribuir para o desenvolvimento de outros princípios como reforçar a atividade independente, ativa e responsável do aluno (DIESEL; MARCHESAN; MARTINS, 2016; GASTARDELLI, 2016).

Observou-se que uma das estratégias mais encontradas foi a Aprendizagem baseada em problemas, sendo que o professor, nesta estratégia busca posicionar-se como um mediador, sendo um guia que estimula os alunos a descobrirem, interpretarem e a aprenderem (MUNHOZ, 2015; AGAPITO; STROHSCHOEN, 2016).

Outra estratégia também observada foi o Educar pela Pesquisa em sala de aula. Esta prevê a participação ativa do aluno na construção do seu conhecimento a partir de questionamentos sistemáticos, buscando desenvolver a argumentação (MORAES; LIMA, 2004). Nos relatos encontrados nas dissertações analisadas, evidencia-se o desenvolvimento da argumentação nos alunos, favorecendo o processo de construção de conhecimento de todos os que convivem no mesmo processo educativo. O aluno é desafiado a apresentar e a defender suas posições, com conteúdo lógico, o que foi observado nas dissertações utilizaram esta estratégia (GEWEHR et al. 2016; OLIVEIRA et al. 2017).

Nas dissertações analisadas foi possível verificar que as estratégias pedagógicas norteadas por metodologias ativas estimulam o desenvolvimento de habilidades, como a autonomia, despertando a curiosidade do aluno. Permitindo assim, o enfoque em capacidades mais profundas e amplas, do que meramente a reprodução de determinados conteúdos (BERBEL, 2011; ANASTASIOU, 2015).

Outra habilidade relatada, nas dissertações analisadas, como tendo sido estimulada pelo uso das estratégias baseadas nas metodologias ativas é a capacidade de reflexão, a qual é uma atividade intelectual e afetiva, onde a partir da exploração de experiências próprias, é possível entendê-las e apreciá-las sob novo enfoque (VICKERY, 2016). A reflexão foi evidenciada principalmente nos trabalhos que utilizaram o diário de bordo, o qual propicia principalmente a atividade reflexiva dos alunos diante de diferentes situações (OLIVEIRA; GEREVINI; STROHSCHOEN, 2017).

Conforme apresentado por Diesel, Marchesan e Martins (2016), observou-se nos relatos apresentados nas dissertações analisadas a preocupação dos professores com a 
proposta de manter o aluno no centro do processo de ensino, promovendo a autonomia deste, sendo o professor mediador, facilitador do processo de aprendizagem. Estímulo à problematização da realidade, com constante reflexão, buscando a interação entre os alunos (DIESEL; MARCHESAN; MARTINS, 2016).

Quanto à postura do professor/pesquisador ao aplicar a metodologia, percebemos que os professores agiram, na maioria dos casos, como mediadores da situação, auxiliando os alunos nas suas dúvidas e não seguindo a postura de um professor tradicional, sendo importante assim para a autonomia dos alunos. Corroborando com essa ideia, Borges e Alencar (2014) explicam que, a partir do momento em que o professor se torna mediador da aprendizagem do aluno, a aprendizagem deixa de ser algo que seja imposto na cabeça dos alunos e se torna um processo onde o professor irá refletir sobre como poderá facilitar a aprendizagem para os alunos e o que terá significado para o mesmo.

\section{Considerações finais}

O presente estudo, objetivou analisar como o desenvolvimento de estratégias pedagógicas inovadoras relacionadas às Metodologias Ativas de ensino e de aprendizagem tem sido levado à prática em pesquisas produzidas por mestrandos vinculados ao Mestrado em Ensino e ao Mestrado Profissional em Ensino de Ciências Exatas de uma Universidade do interior do Estado do Rio Grande do Sul. Problematizando como as propostas de ensino presentes nas dissertações de Mestrado analisadas influenciam no cotidiano da sala de aula e como influenciam os alunos envolvidos, observou-se que as estratégias pedagógicas norteadas por metodologias ativas impulsionaram positivamente o processo de construção de conhecimento pelos alunos. Levou-os a serem mais interessados pelas disciplinas de sala de aula, mais participativos durante as aulas, principalmente por desenvolverem o senso crítico e a autonomia.

Observou-se um número considerado de trabalhos que abordam especificamente este tema nas dissertações, evidenciando a relevância de buscarmos estratégias pedagógicas efetivamente inovadoras, que estimulem os alunos a serem protagonistas no processo de aprendizagem. Salienta-se a importância de estudos deste tipo, que permitam identificar os principais enfoques abordados nas pesquisas desenvolvidas por mestrandos em ensino, revelando os caminhos pelos quais o ensino tem percorrido. 


\section{Referências}

AGAPITO, F. M.; STROHSCHOEN, A. A. G. Aprendizagem baseada em problemas e mapa conceitual: uma experiência com alunos do Curso de pedagogia. Revista Signos, v. 37, n. 2, p. $10-24,2016$.

ANASTASIOU, L. G. C. Metodologia Ativa, Avaliação, Metacognição e Ignorância Perigosa: Elementos para Reflexão na Docência Universitária. Revista Espaço para a Saúde. Londrina, v. 15 n. 1, 2014.

As bases teórico-metodológicas da educação de adultos e os desafios das metodologias ativas nos cursos de graduação. In: MARTINS, Anna Karenina Azevedo; MAPARTIDA, Humberto Miguel Garay (coord.). Metodologias ativas de aprendizagem no ensino superior: relatos e reflexões. São Paulo: Intermeio, 2015.

BRASIL. Ministério da Educação. Instituto Nacional de Estudos e Pesquisas Educacionais Anísio Teixeira - Inep. Estudo exploratório RBPG, sobre o professor brasileiro: com base nos resultados do censo escolar da educação básica 2007. Brasília: Inep, 2009.

BARBOSA, E.F.; MOURA, D.G. Metodologias ativas de aprendizagem na Educação Profissional e Tecnológica. Boletim Técnico Senac, Rio de Janeiro, v. 39, n.2, p.48-67, maio/ago. 2013.

BERBEL, N. A. N. A problematização e a aprendizagem baseada em problemas: diferentes termos ou diferentes caminhos? Interface - Comunicação, Saúde, Educação, v.2, n.2, 1998.

As metodologias ativas e a promoção da autonomia de estudantes. Semina: Ciências Sociais e Humanas, Londrina, v. 32, n. 1, p. 25-40, jan./jun. 2011.

BERGMAN, J.; SAMS, A. Sala de aula invertida: uma metodologia ativa de aprendizagem. 1 ed. Rio de Janeiro: LTC, 2016.

BORGES, T. S., ALENCAR, G. Metodologias Ativas na Promoção da Formação Crítica do Estudante: o Uso das Metodologias Ativas como Recurso Didático na Formação Crítica do Estudante do Ensino Superior. Cairu em Revista, (03) 04, p. 1 19-143, 2014.

BONWELL, C. C.; EISON, J. A. Active learning: creating excitement in the classroom. Washington, DC: Eric Digests, 1991. Publication Identifier ED340272. Disponível em: <http://www.eric.ed.gov/PDFS/ED340272.pdf>. Acesso em: 02 agosto 2017.

DAROIT, H. A pesquisa no ensino de física como ferramenta pedagógica para a construção da autonomia. 2010. Dissertação (Mestrado) - Curso de Ensino de Ciências Exatas, Centro Universitário UNIVATES, Lajeado, 07 abr. 2010. Disponível em: <http://hdl.handle.net/10737/108>

DIESEL, A.; BALDEZ, A. L. S.; MARTINS, S N. Os princípios das metodologias ativas de ensino: uma abordagem teórica. Revista Thema, v. 14, n. 1, p. 268-288, fev. 2017.

DIESEL, A.; MARCHESAN, M. R.; MARTINS, S. N. Metodologias ativas de ensino na sala de aula: um olhar de docentes da Educação Profissional técnica de nível médio. Signos, v. 37, n.1, p.153-169, 2016. 
GASTARDELLI, G. Metodologias ativas: desafios para uma educação disruptiva. 1 ed. Porto Alegre: Propale. 2016.

GEMIGNANI, E.Y.M.Y. Formação de Professores e Metodologias Ativas de EnsinoAprendizagem: Ensinar Para a Compreensão. Revista Fronteira das Educação [online], Recife, v. 1, n. 2, 2012. ISSN: 2237-9703. Disponível em: <http://www.fronteirasdaeducacao.org/index.php/fronteiras/article/view/14>. Acesso em: 10 jul. 2017.

GEWEHR, D.; STROHSCHOEN, A. A. G.; MARCHI, M. I.; MARTINS, S. N.; SCHUCK, R. Metodologias ativas de ensino e de aprendizagem: uma abordagem de iniciação à pesquisa. Ensino \& Pesquisa, v. 14, n.1, p. 225-246, 2016.

GIL, A.C. Como elaborar projetos de pesquisa. 4. ed. São Paulo: Atlas, 2008.

GODOY, A. S. Introdução À Pesquisa Qualitativa e suas Possibilidades. Revista de Administração de Empresas São Paulo, v. 35, n. 2, p. 57-63, 1995.

GOMES, A. P.; ARCURI, M.B.; CRISTEL, E.C.; RIBEIRO, R.M.; SOUZA, L.M.B.da M.; SIQUEIRA-BATISTA, R. Evaluation in medical education: the role of the portfolio in curricula based on active methodologies. Rev. bras. educ. med., Rio de Janeiro , v. 34, n. 3, p. 390-396, 2010

<http://www.scielo.br/scielo.php?script=sci_arttext\&pid=S0100-

Disponível

em

$55022010000300008 \& \operatorname{lng}=$ en\&nrm=iso >. Acesso em 11 jul. 2017.

HENNEMANN, N. R. "Fontes de energia e ambiente: uma proposta interdisciplinar no Ensino de Ciências Exatas". 2012. Dissertação (Mestrado) - Curso de Ensino de Ciências Exatas, Centro Universitário UNIVATES, Lajeado, 27 abr. 2012. Disponível em: <http://hdl.handle.net/10737/282>.

KAFER, G. A. Ambiente virtual de aprendizagem: possibilidades e desafios no ensino de química. 2015. Dissertação (Mestrado) - Curso de Ensino de Ciências Exatas, Centro Universitário UNIVATES, Lajeado, 30 jul. 2015. Disponível em: <http://hdl.handle.net/10737/973>.

MAGEDANZ, A. "Sala de aula presencial e ambiente virtual de aprendizagem: investigando interações de alunos do ensino médio, a partir de uma proposta diferenciada no estudo de Matemática". 2009. Dissertação (Mestrado) - Curso de Ensino de Ciências Exatas, Centro Universitário UNIVATES, Lajeado, 29 jul. 2009. Disponível em: <http://hdl.handle.net/10737/86>.

MASETTO, M. T. Competência pedagógica do professor universitário. São Paulo: Summus, 2003.

MARTINEZ, R. S.; SOUZA, H. J. S.; TONIOSSO, J. P. A Construção Colaborativa do Conhecimento e a Geração de Ideias: O "World Café" No Centro Universitário Unifafibe de Bebedouro-SP. Fórum das metodologias ativas. Anais.... Pontifícia Universidade Católica de São Paulo: São Paulo, 2015. Disponível em: <http://www.pucsp.br/sites/default/files/download/anais_forum_metodologias_ativas_2015.p df $>$ Acesso em 02 agosto de 2017.

MARTINS, I. de A. M. "Utilização de práticas pedagógicas diferenciadas no ensino de Matemática Financeira: um estudo de caso no Instituto Maranhense de Ensino e 
Cultura - IMEC". 2016. Dissertação (Mestrado) - Curso de Ensino de Ciências Exatas, Centro Universitário UNIVATES, Lajeado, 05 ago. 2016. Disponível em: <http://hdl.handle.net/10737/1160>.

MAZUR, E. Peer instruction: a revolução da aprendizagem ativa. Porto Alegre: Penso, 2015.

MORAES, R.; LIMA, V. M. do R. (orgs). Pesquisa em sala de aula: tendências para a Educação em Novos Tempos. EDIPUCRS. 2 ed. 2004.

MORO, F. T. Atividades experimentais e simulações computacionais: integração para a construção de conceitos de transferência de energia térmica no Ensino Médio. 2015. Dissertação (Mestrado) - Curso de Ensino de Ciências Exatas, Centro Universitário UNIVATES, Lajeado, 18 dez. 2015. Disponível em: <http://hdl.handle.net/10737/1086>

MUNHOZ, A. S. ABP: Aprendizagem baseada em problemas: ferramentas de apoio ao docente no processo de ensino e aprendizagem. São Paulo: Cengage Learning, 2015.

OLIVEIRA, A. M.; GEREVINI, A. M.; STROHSCHOEN, A. A. G. Diário de bordo: uma ferramenta metodológica para o desenvolvimento da alfabetização científica. Revista Tempos e Espaços em Educação. v. 10, n. 22, p. 119-132, 2017.

OLIVEIRA, A. M. de; RODRIGUES, A. B. L.; REIS, E. F.; STROHSCHOEN, A. A. G. Ensino pela pesquisa na escola: proposta para produção e utilização de esterco animal. Experiências em Ensino de Ciências, v.12, n.7, p. 141-153, 2017.

PINTO, A. S. S; BUENO, M. R. P.; SILVA, M. A. F. A.; MENEZES, M. Z. S.; KOEHLER, S. M. F. O laboratório de metodologias inovadoras e sua pesquisa sobre o uso de metodologias ativas pelos cursos de licenciatura do UNISAL, Lorena: estendendo o conhecimento para além da sala de aula. Revista de Ciências da Educação, v. 2, n. 29, p. 67 79, jun-dez 2013.

ROSSI, T. V. "Jogo interativo: espaço de construção do conhecimento matemático e do convívio com o outro". 2012. Dissertação (Mestrado) - Curso de Ensino de Ciências Exatas, Centro Universitário UNIVATES, Lajeado, 30 nov. 2012. Disponível em:

$<$ http://hdl.handle.net/10737/297>.

SCHUCK, R. J.; MARTINS, S.N.; MARCHI, M.I.; GRASSI, M.H. Ensino em mestrado profissional de Ciências Exatas: concepções e saberes de professores em formação. RBPG, Brasília, v.13, n. 31, p. 491 - 506, 2016.

SCORSATTO, M.C. "Uma abordagem alternativa para o ensino da física: consumo racional de energia". 2010. Dissertação (Mestrado) - Curso de Ensino de Ciências Exatas, Centro Universitário UNIVATES, Lajeado, 31 ago. 2010. Disponível em: <http://hdl.handle.net/10737/117>.

SILBERMAN, M. Active learning: 101 strategies do teach any subject. Massachusetts: Pearson, 1996.

SIQUEIRA, A. P. T. "Ações interativas no âmbito de uma escola ciclada e suas implicações na formação de professores e estudantes". 2009. Dissertação (Mestrado) - 
Curso de Ensino de Ciências Exatas, Centro Universitário UNIVATES, Lajeado, 08 abr. 2009. Disponível em: 〈http://hdl.handle.net/10737/77>.

SOBRAL, F. R.; CAMPOS, C. J. C. Utilização de metodologia ativa no ensino e assistência de enfermagem na produção nacional: revisão integrativa. Rev Esc Enferm USP; v.46 n.1,p. 208-18, 2012.

SOUZA, R. G. de. "Protagonismo infantil e saberes culturais ribeirinhos no ensino de Matemática na Educação Infantil". 2016. Dissertação (Mestrado) - Curso de Ensino de Ciências Exatas, Centro Universitário UNIVATES, Lajeado, 28 out. 2016. Disponível em: <http://hdl.handle.net/10737/1571>.

SOUZA, C. S.; IGLESIAS, A. G.; PAZIN-FILHO, A. Estratégias inovadoras para métodos de ensino tradicionais - aspectos gerais. Medicina, v. 47, n. 3, p. 284-292, 2014.

VALENTE, J. A. Blended learning e as mudanças no ensino superior: a proposta da sala: a proposta da sala de aula invertida. Educar em Revista, Curitiba, Brasil, Edição Especial n. 4, p. 79-97, 2014.

VICKERY, A. Aprendizagem ativa nos anos iniciais do ensino fundamental. Porto Alegre: Penso, 2016.

WALL, M. L.; PRADO, M; L.; CARRARO, T. E. A experiência de realizar um Estágio Docência aplicando metodologias ativas. Acta Paulista de Enfermagem, v.21, n.3, p. 515519, 2008. 